\title{
Of the importance of the clinical phenotypes in the interpretation of the studies dealing with Fabry disease
}

\author{
Wladimir Mauhin ${ }^{1,2^{*}}$ (D) Olivier Lidove ${ }^{1,2}$ and Olivier Benveniste ${ }^{2}$
}

\begin{abstract}
Fabry disease (OMIM \#301500) is an X-linked disorder caused by alpha-galactosidase A deficiency with two major clinical phenotypes: classic and non-classic of different prognosis. From 2001, enzyme replacement therapies with agalsidase alfa and beta have been available. In this letter we underline the different clinical and technical considerations the readers have to be aware of to interpret the results of studies dealing with Fabry disease and anti-agalsidase antibodies. We reaffirm that antibodies preferentially develop in the severe classic Fabry phenotype, which can mislead into interpreting that antibodies are associated with much severe clinical events.
\end{abstract}

Keywords: Fabry disease, Antibodies, Inhibition, Phenotype

\section{Dear Editors}

We read with interest the letter from Lenders et al. concerning our recent article entitled "Deep characterization of the anti-drug antibodies developed in Fabry disease patients, a prospective analysis from the French multicenter cohort FFABRY" $[1,2]$. In the letter, our main message seems to have been eluded: the development of anti-drug antibodies (ADAs) depends on the clinical phenotype (ADA-positivity in classic patients $58.6 \%$ vs $6.7 \%$ in non-classic patients, $p<0.001$ ). Also, with the limits of a time-point study, after stratification on the clinical phenotype, we did not observe any obvious clinical event associated with the presence of ADAs. It is essential to remind that patients with a classical phenotype are more prone to develop a severe renal disease. In our cohort, all the kidney transplanted patients belonged to the classic group, independently from any ADA (see Fig. 1). Also we should have mentioned that 2 ADA-positive patients had benefited from a renal graft before the introduction of enzyme replacement therapy (ERT), suggesting an obvious severe disease prior to the development of antibodies. Concerning the exposure to ERT, the letter

\footnotetext{
* Correspondence: wladmauhin@gmail.com

${ }^{1}$ Internal Medicine Department, Groupe hospitalier Diaconesses Croix Saint Simon, 125 rue d'Avron, 75020 Paris, France

${ }^{2}$ Sorbonne Université, INSERM, UMR 974, Centre of Research in Myology, Association Institut de Myologie, Pitié-Salpêtrière University Hospital, 75013 Paris, France
}

mentions that "more ADA-positive patients were treated with agalsidase beta", which is wrong: as mentioned in our article, there was no difference in terms of seroprevalence in the different treatment group (alfa $30.8 \%$, beta $44.4 \%$, alfa and beta $42.9 \%, p=0.7$ ). There was also no difference in the mean infused dose received by patients during their whole exposure to ERT (ADA-positive vs ADA-negative patients 0.43 $\mathrm{mg} / \mathrm{kg}$ vs $0.64 \mathrm{mg} / \mathrm{kg}, \mathrm{p}=\mathrm{ns}$ ).

We agree with Lenders and colleagues that purifying IgG subclasses could bring essential information concerning immunogenicity as a first approach. Also, it appears that this has not been performed in the referenced paper [3] where authors used purified total IgGs. We also agree with the authors that ADAs do not possess a mandatory neutralizing activity. This is the reason why we think that inhibition assays should only be performed after a first step using an immune-based assay such as an ELISA. Our goal was to study all ADAs, neutralizing and non-neutralizing. We may have to clarify that we did perform inhibition assay in all the men, contrary to what is mentioned in the letter. As expected, any of the antibody-negative serum was associated with enzymatic inhibition (Fig. 4a). It should also be reminded to readers that there is no consensus for inhibition assay and that the percentage of enzyme inhibition depends on the concentrations of 
ERT used in the protocol of the inhibition assay. Therefore, there is a need to standardize the protocol and the threshold retained to define inhibition.

In summary, we cannot conclude that antibodies (not only neutralizing) are associated with clinical events in our cohort in this time-point study.

\section{Abbreviations \\ ADA: Anti-drug antibodies; ERT: Enzyme replacement therapy}

\section{Funding}

Not applicable.

\section{Availability of data and materials}

The datasets generated and/or analysed during the current study are not publicly available due to the individual person's data that are involved but are available from the corresponding author on reasonable request.

\section{Authors' contributions}

WM, OL and OB designed the study, performed the experiments, interpreted the data, drafted the manuscript and approved this final version.

Ethics approval and consent to participate

Legal authorizations were obtained from the Comité consultatif sur le traitement de l'information en matière de recherche dans le domaine de la santé ( $\left.n^{\circ} 14.324 \mathrm{bis}\right)$ and the Comité de Protection des personnes Paris VI, according to the relevant French legislation.

All patients signed written consent after specific oral and written

information, for this research and its publication.

\section{Consent for publication}

All patients signed written consent after specific oral and written information, for this research and its publication.

\section{Competing interests}

Inserm U974 research team received financial support from Shire, AFM-

Téléthon, SNFMI (Société Nationale Française de Médecine Interne) and VML (Vaincre les Maladies Lysosomales) for this study.

Wladimir Mauhin: Travel fees and accommodations: Shire, Orphan Europe, Amicus, Sanofi-Genzyme, honorarium: Shire.

Olivier Lidove: Travel fees, accommodations and honorarium: Shire, SanofiGenzyme; honorarium: Amicus.

Olivier Benveniste: Travel fees Shire, LFB, CSL Behring; honorarium: Novartis, Neovacs, LFB.

\section{Publisher's Note}

Springer Nature remains neutral with regard to jurisdictional claims in published maps and institutional affiliations.

Received: 6 December 2018 Accepted: 12 December 2018

Published online: 07 January 2019

\section{References}

1. Mauhin W, Lidove O, Amelin D, Lamari F, Caillaud C, Mingozzi F, et al. Deep characterization of the anti-drug antibodies developed in Fabry disease patients, a prospective analysis from the French multicenter cohort FFABRY. Orphanet J Rare Dis 31 juill. 2018;13(1):127.

2. Lenders M, Schmitz B, Brand S-M, Brand E. Neutralizing anti-drug antibodies in Fabry disease have no obvious clinical impact? Orphanet J Rare Dis. 2018; 13(1):171.

3. Lenders M, Schmitz B, Brand S-M, Foell D, Brand E. Characterization of drugneutralizing antibodies in patients with Fabry disease during infusion. J Allergy Clin Immunol. 2018;141(6):2289-2292.e7. 